\title{
PREVALENCE AND CHARACTERISTICS OF TONSILLAR CALCIFICATIONS VISIBLE IN DENTAL PANORAMIC RADIOGRAPHS IN A SAMPLE OF POLISH POPULATION
}

\author{
Katarzyna Portka, Ingrid Różyło-Kalinowska \\ Department of Dentomaxillofacial Radiology, Medical University of Lublin, Poland
}

\begin{abstract}
INTRODUCTION: Calcifications found in the crypts of palatal tonsils, called tonsilloliths, are considered an incidental finding in panoramic radiographs. Dentists and radiologists should be aware of their radiological appearances in order to avoid diagnosis of different calcifications.

ОвјестіvEs: The objective of the research was to examine the prevalence and characteristics of tonsillar calcifications visible in panoramic radiographs in a sample of Polish population.

MATERIAL AND METHODs: The study included one thousand consecutive digital dental panoramic radiographs taken with Planmeca Prostyle X-ray machine in 577 females and 423 males aged from 5 to 88 years. The presence of tonsilloliths, their characteristics (single or multiple) as well as localization according to 6 regions (1-3 shadows cast on the mandibular ramus above, at and below the level of soft palate, 4 - below mandible, 5 - below and posterior to mandibular angle, 6 - posterior to mandibular ramus) were assessed.

RESULTs: Tonsilloliths were detected in over $24 \%$ of panoramics. Prevalence in females and males was comparable. Findings were more prevalent in the following age groups: $30-39$ years, $50-59$ years (37.5\%), and $40-49$ years (35\%). They were far less frequent in patients below 30 years of age. Tonsillar calcifications were found in 511 regions in 242 patients, and in 116 cases they were single. Almost $30 \%$ of calcifications were detected in region 2 and $25 \%$ in region 3 . Over $65 \%$ of tonsilloliths were found bilaterally.

Conclusions: Tonsilloliths are frequent incidental finding in X-rays. About one-quarter of analyzed panoramics revealed the presence of stones.
\end{abstract}

KEY WORDS: palatine tonsil, tonsilloliths, dental panoramic radiograph.

J Stoma 2020; 73, 1: 27-31

DOI: https://doi.org/10.5114/jos.2020.94174

\section{INTRODUCTION}

One type of calcifications that are found in maxillofacial region are stones in palatal tonsils. Tonsilloliths (TLs) are calcifications, which arise from mass of epithelium, serum, bacteria, and organic debris in palatine tonsillar crypts. They may be asymptomatic or cause dysphagia, globus sensation, halitosis, otalgia, peritonsil- lar abscess, swelling in the tonsillar fossa, glossopharyngeal neuralgia, orofacial pain, upper airway obstruction, and sleep breathing disorders. They may be incidentally found in three- and two-dimensional radiological examinations [1-13]. TLs appear as small opacities, overlapping the middle portion of mandible ramus, or as multiple poorly defined radio-opacities, which may be oval, round, or irregular in shape, superimposed on the soft

JOURNAL OF STOMATOLOGY CZASOPISMO STOMATOLOGICZNE

ADDRess FOR CORRESPONDENCE: Katarzyna Portka, Department of Dentomaxillofacial Radiology, Medical University of Lublin, Poland, e-mail: denkiewicz.katarzyna@gmail.com

ReCEIVED: 18.03.2020 • ACCEPTED: 23.03.2020 • PUBLISHED: 31.03 .2020 
tissues' shadows. Their borders are poorly defined, and densities vary from slightly radiopaque to close in intensity to the cancellous bone $[8,14,15]$. Changliang et al. [15] showed that the density of majority of tonsilloliths was over 120 Hounsfield units (HU) in computed tomography (CT) scans.

Overall calcifications in soft tissues in the maxillofacial region are uncommon, and generally correspond to radiographic findings in examinations such as panoramic radiograph. Nowadays, dental panoramic radiograph is an inherent diagnostic tool in correlation with the clinical examination, which reveals general condition of teeth and surrounding structures in maxillofacial region. The most important features of diagnostic evaluation are location, distribution, number, size, and shape of the calcifications [16]. Differential diagnosis for radiological image of TLs in maxillofacial region include sialoliths of the submandibular glands, carotid artery calcifications, calcified submandibular lymph nodes, or other foci of idiopathic osteosclerosis $[1,11,16]$.

\section{OBJECTIVES}

The objective of present study was to examine occurrence and characteristics of tonsilloliths, as inciden-

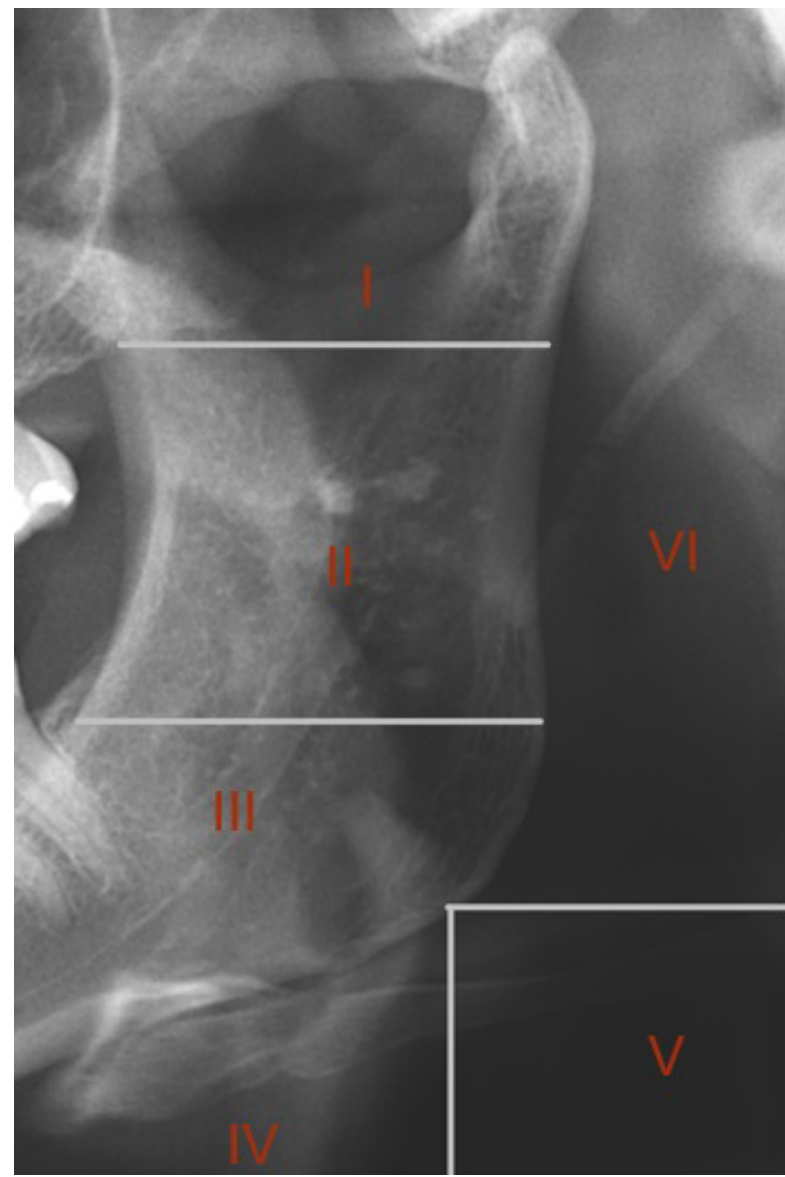

FIGURE 1. Regions of presence of tonsilloliths tal findings on dental digital panoramic radiographs in a sample of Polish population.

\section{MATERIAL AND METHODS}

The material of the study consists of one thousand consecutive digital dental panoramic radiographs taken by Planmeca Prostyle (Finland) X-ray machine in 577 females and 423 males aged from 5 to 88 years. The radiographs were taken in the Department of Dentomaxillofacial Radiology at the Medical University of Lublin. Examinations were prescribed due to various clinical reasons. We excluded images with technical errors and any pathological lesions in examined regions. The group of patients was selected into nine age range categories, between 5-9 years old and 80-89 years old.

The presence and localization of tonsilloliths were assessed by one observer. Each image of mandible was bilaterally divided into 6 regions: 1 - shadows cast above the mandibular ramus, 2 - at the level of soft tissue, 3 - below the level of soft palate, 4 - below mandible, 5 - below and posterior mandibular, and 6 - posterior mandibular ramus [17]. Tonsilloliths were classified according to the areas (Figure 1).

\section{RESULTS}

Among one thousand examined radiographs, tonsilloliths were detected in 242 of X-rays (24.2\%) in all age groups. The highest prevalence of calcifications was found in patients in two age groups: $50-59$ years (37.5\%) and $30-39$ years $(37.4 \%)$; the least in 9-year-old's children $(3.3 \%)$ (Table 1$)$.

The group with palatine tonsil stones included 142 females and 100 males, which constituted $24.6 \%$ of examined women and $23.6 \%$ of men. Thus, no gender predilection was found in the study group.

One hundred twenty-six patients had calcifications in more than one region. In total, they were present in 511 regions (Table 2 ).

Calcifications were prevalent in mandibular ramus, on the level of soft palate $(64.97 \%)$ and below soft palate $(24.27 \%$ ) (Figure 2). Next was the area below and backwards from the angle of mandible, with thirty-four (6.65\%) tonsilloliths observed (Figure 3).

In 158 radiographs (65.3\%), stones were observed bilaterally (Figures 4 and 5). Forty-three calcifications were found on the right side (17.8\%), while 41 (16.9\%) on the contralateral side.

A smaller percentage of calcifications $(2.15 \%)$ was observed posteriorly to the ramus of mandible. Only six calcifications occurred at the level of mandible, above the soft palate $(1.17 \%$ of all palatine tonsil stones). Only in four cases $(0.78 \%)$, calcifications were visible below the body of mandible. 


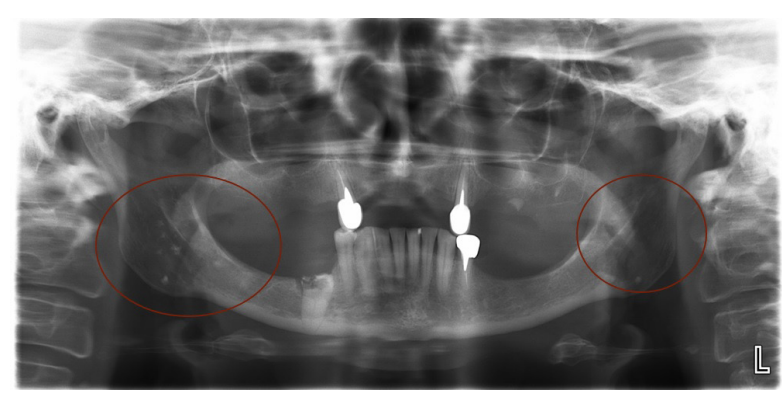

FIGURE 2. Tonsilloliths cast bilaterally on the mandibular ramus at the level of soft palate and below

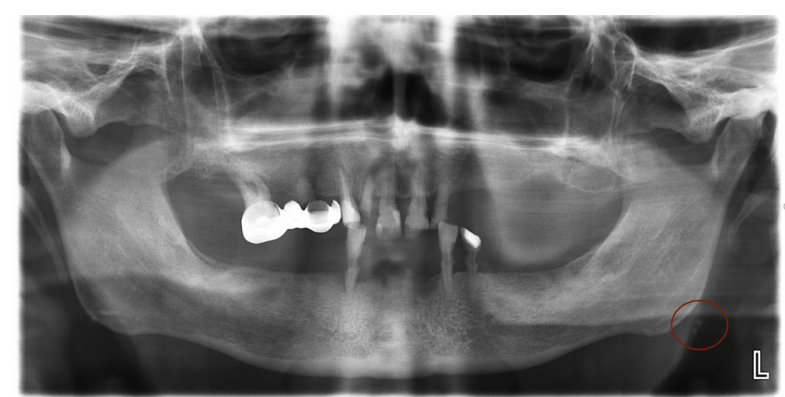

FIGURE 3. Tonsilloliths found in region 5

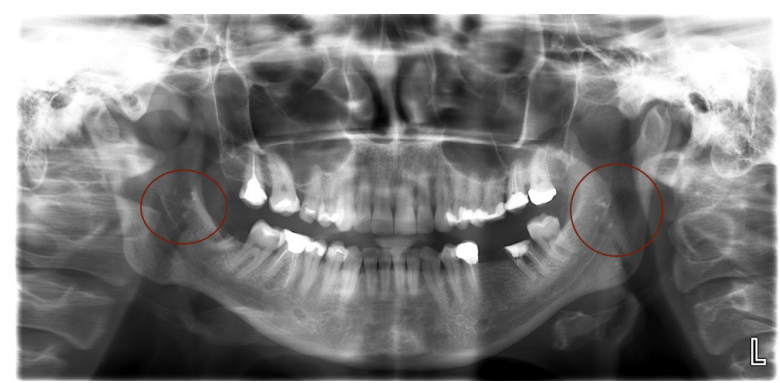

FIGURE 4. Bilateral tonsilloliths in region 2

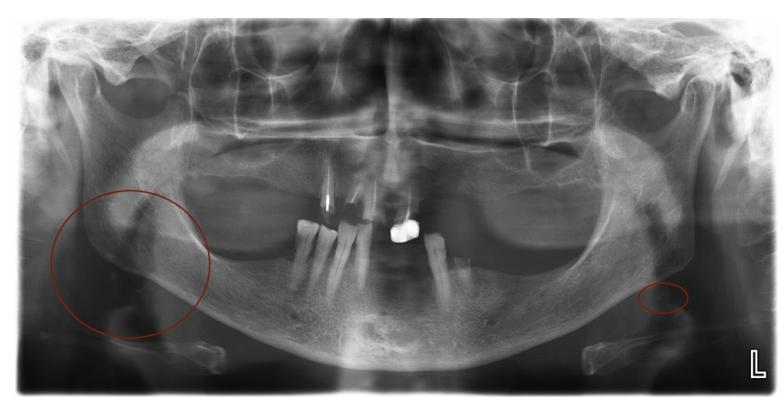

FIGURE 5. Bilateral calcifications in palatal tonsils in region 4, furthermore on the right side in region 3

\section{DISCUSSION}

Calcifications in maxillofacial region such as tonsilloliths may be incidental findings in X-ray panoramic radiographs in daily practice, whenever there is an indi-
TABLE 1. Classification of the patients to age groups

\begin{tabular}{|l|c|c|c|}
\hline $\begin{array}{l}\text { Age group } \\
\text { (years) }\end{array}$ & Patients with TLs & All patients & Percentage \\
\hline$<9$ & 2 & 61 & 3.3 \\
\hline $10-19$ & 20 & 173 & 11.6 \\
\hline $20-29$ & 49 & 287 & 17.1 \\
\hline $30-39$ & 49 & 131 & 37.4 \\
\hline $40-49$ & 41 & 116 & 35.3 \\
\hline $50-59$ & 39 & 104 & 37.5 \\
\hline $60-69$ & 27 & 78 & 34.6 \\
\hline $70-79$ & 8 & 29 & 27.6 \\
\hline $80-89$ & 7 & 21 & 33.3 \\
\hline Total & 242 & 1,000 & 24.2 \\
\hline TLs-tonsilloliths & & & \\
& & &
\end{tabular}

TABLE 2. The number and percentage of tonsilloliths (TLs) found in specific regions

\begin{tabular}{|l|c|c|}
\hline Region & Number of TLs & Percentage \\
\hline 1 & 6 & 1.17 \\
\hline 2 & 332 & 64.97 \\
\hline 3 & 124 & 24.27 \\
\hline 4 & 4 & 0.78 \\
\hline 5 & 34 & 6.65 \\
\hline 6 & 11 & 2.15 \\
\hline Total & 511 & 100 \\
\hline
\end{tabular}

cation [18]. Previous studies reported that the detection of palatine tonsilloliths varies, and the prevalence in CT is $16.0-46.6 \%$ and in panoramic radiographs $-7.3-13.4 \%$ only [7]. Two-dimensional image, superimposition of structures, distortion, and magnification may be diagnostic challenges in interpretation of panoramic radiographs $[2,9,13,19]$. The detection of TLs in panoramic radiographs might be related to their amount, degree of calcification, or size [4].

Takahashi et al. [17] evaluated 2,244 panoramic radiographs, and stones in palatal tonsils were found in 300 of these (13.4\%), while in our study, it was $24.2 \%$. TLs were predominantly superimposed on the level of the soft palate in 176 patients (49.9\%), inferior to the level of the soft palate in 90 individuals $(25.5 \%)$ in the quoted study.

Aoun et al. [20] studied 500 digital panoramic radiographs of Lebanese adult patients (281 females and 219 males), with an average age of 47.9 years. Authors found TLs in 36 radiographs (7.2\%), with 18 females and the same number of males. Thirteen cases were located on the right side, twelve on the left side, and eleven bilaterally. Affected patients' age ranged from 
24 to 84 years (mean, 61 years). There was no statistically significant relation between stones presence and gender. Moreover, a low positive correlation between tonsilloliths and age $(r=0.193)$ was observed. Twodimensional examination may be used for early diagnosis of calcifications, but in order to confirm the findings, more detailed imaging is needed. Three dimensional scans are a good option to provide precise diagnosis of calcifications, especially symptomatic ones [1].

Schreiner-Tiefenbacher et al. [1] examined panoramic radiographs and cone-beam computed tomography (CBCT) scans of 822 patients. If one or more calcifications in panoramic radiograph were found, CBCT was evaluated. The study group consisted of $43.8 \%$ men and $56.2 \%$ women, divided into three following age groups: $21-39$ years (16.7\%), 40-59 years (48.9\%), and $60-89$ years $(34.4 \%)$. The authors analyzed the presence of tonsilloliths, sialoliths of the submandibular salivary gland, carotid artery calcifications (CAC), calcified submandibular lymph nodes, and any other idiopathic osteosclerosis. At least one calcification was detected in panoramic radiographs of 415 patients. Tonsilloliths were visible in diagnosed calcifications in 249 (30.2\%) examinations and their presence was confirmed in 121 (29.2\%) three-dimensional volumes. Predominantly, they were bilateral, and more common in women than men. It was in $38.7 \%$ of accordance between TLs diagnosed on the CBCT and panoramic radiographs and the tonsilloliths diagnosed in CBCT.

Oda et al. [4] in a study with 482 pairs of panoramic radiographs and CT scans compared the occurrence and characteristics of tonsilloliths. Among 482 patients, $222(46.1 \%)$ were classified to group with calcifications in palatine tonsils in CT scans, while TLs were found only in $37(7.7 \%)$ panoramics. The authors observed 185 cases of disagreement between two- and three-dimensional imaging. It was supposed that density in Hounsfield units and size of stone might explain the detection in CT images only. Certainly, there was a significant correlation between the Hounsfield units value and the detection of tonsilloliths in panoramics (Spearman $r=0.429 ; p<0.0001)$. The higher CT number, the higher tonsilloliths detection rate, which means that denser stones were more detectable in radiographs. Ninety-five cases with density beneath $300 \mathrm{HU}$ were not visible on panoramic radiographs for the observer. The authors found significant correlation between size and tonsilloliths detection rate on panoramic radiographs (Spearman $r=0.318 ; p<0.0001$ ), which was higher as the size of stones increased.

Kim et al. [8] analyzed 3,886 CT scans and reported palatine tonsilloliths in 1,179 of cases (30.3\%). Five hundred fifty $(33.3 \%)$ patients were male and 629 (28.2\%) were female. The prevalence of tonsilloliths was significantly higher in men than in women $(p<0.05)$. The mean age of the patients with tonsilloliths was 39.8 years. Tonsilloliths were detected bilaterally in 392 pa- tients (33.2\%), and 430 of stones were located unilaterally on the right side and 357 on the left. There was no significant difference in prevalence between the right and left sides.

Tonsilloliths in palatine tonsils are often diagnosed, but it is important to be aware of the possibility of presence of calcifications in lingual tonsils in panoramic radiographs [21].

Lee and Mandel [21] reported a case of a 71-year-old man, whose panoramic radiograph showed 2 opacities bilaterally present in soft tissues, posteriorly to the angle of mandible. CT confirmed the existence of two tonsilloliths in lingual tonsil. Bilateral calcifications were noted in two-dimensional image, because the opacities on the right side were "ghost shadows" of the left side calcifications. "Ghost shadows" are examined objects, which arise when these objects are not inside the focal trough of the panoramic unit.

Missias et al. [24] studied prevalence of soft tissue calcifications in the maxillofacial region detected by CBCT. The following conditions were evaluated: tonsilloliths, calcified stylohyoid ligament, elongated styloid process, calcified triticeous cartilage, sialoliths, calcified carotid artery atheroma, calcinosis cutis, calcified superior cornu of thyroid cartilage, antroliths, phleboliths, and calcified lymph nodes. They examined 224 maxillary and mandibular CBCTs, 484 of maxilla and 292 of mandibular CBCTs only. Tonsilloliths were found in $69(30.8 \%), 100(20.7 \%)$, and $72(24.7 \%)$ of these examinations, respectively.

On the base of analyzed studies, where results of 2-dimensional and 3-dimensional examinations were compared, the effectiveness of CBCT and CT are unquestionable. The main limitation of our study is the use of panoramic images and not CBCT. However, our paper aimed at highlighting the necessity of comprehensive analysis of panoramic radiographs, as these $\mathrm{X}$-rays are commonly taken radiographs in dental office settings.

\section{CONCLUSIONS}

Calcifications in the palatine tonsils are a common incidental finding in panoramic images. Radiological images of calcifications are superimposed on both hard and soft tissue shadows, and the occurrence of tonsil stones is similarly observed in women and men. In many cases, radiological image of calcifications in palatine tonsils helps in correct interpretation of images calcification in this localization.

\section{CONFLICT OF INTEREST}

The authors declare no potential conflicts of interest with respect to the research, authorship, and/or publication of this article. 


\section{References}

1. Schreiner-Tiefenbacher B, Forster V, Pauli K, et al. Evaluation of mandibular calcification on 3D volume images. Heliyon 2019; 5: e01698.

2. Cho W, Park H. Transoral sonographic diagnosis of tonsilliliths. Report of 3 cases. J Ultrasound Med 2013; 32: 2037-2042.

3. Freire JL, França SR, Teixeira FW, et al. Prevalence of calcification of the head and neck soft tissue diagnosed with digital panoramic radiography in northeast brazilian population. Minerva Stomatol 2019; 68: 17-24.

4. Oda M, Kito S, Tanaka T, et al. Prevalence and imaging characteristics of detectable tonsilloliths on 482 pairs of consecutive CT and panoramic radiographs. BMC Oral Health 2013; 13: 54-62.

5. Misirloglu M, Nalcaci R, Adisen MZ, et al. Bilateral and pseudobilateral tonsilloliths: Three dimensional imaging with cone-beam computed tomography. Imaging Sci Dent 2013; 43: 163-169.

6. Abdelkarim AZ, Lozanoff S, Abu el Sadat SM, et al. Osteoma cutis and tonsillolith: a cone beam computed tomography study. Cureus 2018; 10: e3003.

7. Takahashi A, Sugawara C, Akita K. Prevalence and imaging characteristics of nasopharyngeal and eustachian tube tonsilloliths in 2244 patients determined using computed tomography. Dentomaxillofac Radiol 2018; 4: 20180052.

8. Kim MJ, Kim JE, Huh KH, et al. Multidetector computed tomography imaging characteristics of asymptomatic palatine tonsilloliths: a retrospective study on 3886 examinations. Oral Maxillofac Radiol 2018; 125: 693-698.

9. Cazas-Duran EV, Fischer Rubira-Bullen IR, Pagin O, et al. Cleft lip and palate subjects prevalence of abnormal stylohyoid complex and tonsilloliths on cone beam computed tomography. Acta Otorinolaringol Esp 2018; 69: 61-66.

10. Takahashi A, Sugawara C, Kudoh K, et al. Lingual tonsillolith: prevalence and imaging characteristics evaluated on 2244 pairs of panoramic radiographs and CT images. Dentomaxillofac Radiol 2018; 47: 20170251

11. Kajan ZD, Sigaroudi AK, Mohebbi M. Prevalence and patterns of palatine and adenoid tonsilloliths in cone-beam computed tomography images of an Iranian population. Dent Res J 2016; 13: 315-321.

12. Ghabanchi J, Haghnegahdar A, Khojastehpour L, et al. Frequency of tonsilloliths in panoramic views of a selected population in Southern Iran. J Dent Shiraz UnivMed Sci 2015; 16: 75-80.

13. Takahashi A, Sugawara C, Kudoh T, et al. Prevalence and imaging characteristics of palatine tonsilloliths detected by CT in 2,873 consecutive patients. Sci World J 2014; 2014: 94090; doi: 10.1155/ 2014/940960.

14. Ribeiro A, Keat R, Khalid S, et al. Prevalence of calcifications in soft tissues visible on a dental pantomogram: a retrospective analysis. J Stomatol Oral Maxillofac Surg 2018; 119: 369-374.

15. Changliang Y, Longxiang T, Xiaohu L, et al. Prevalence of tonsilloliths and CT diagnosis. Chin J Otorhinolaryngol Head Neck Surg 2017; 52: 604-607.

16. Garay I, Netto HD, Olate S. Soft tissue calcified in mandibular angle area observed by means of panoramic radiography. Int J Clin Exp Med 2014; 7: 51-56.

17. Takahashi A, Sugawara C, Kudoh T, et al. Prevalence and imaging characteristics of palatine tonsilloliths evaluated on 2244 pairs of panoramic radiographs and CT images. Clin Oral Invest 2017; 21: 85-91.

18. Sutter W, Berger S, Meier M, et al. Cross-sectional study on the prevalence of carotid artery calcifications, tonsilloliths, calcified submandibular lymph nodes, sialoliths of the submandibular gland, and idiopathic osteosclerosis using digital panoramic radiography in a lower Austrian subpopulation. Quintessence Int 2018; 49: 227-238.

19. Centurion BS, Imada TSN, Pagin O, et al. How to assess tonsilloliths and styloid chain ossifications on cone beam computed tomography images. Oral Dis 2013; 19: 473-478.
20. Aoun G, Nasseh I, Diab HA, et al. Palatine tonsilloliths: a retrospective study on 500 digital panoramic radiographs. J Contemp Dent Pract 2018; 19: 1284-1287.

21. Lee KC, Mandel L. Lingual (not palatine) tonsillolith. J Oral Maxillofac Surg 2019; 77: 1650-1654.

22. Missias EM, Nascimento EHL, Pontual MLA, et al. Prevalence of soft tissue calcifications in the maxillofacial region detected by cone beam CT. Oral Dis 2018; 24: 628-637. 